\title{
Material decomposition using iodine quantification on spectral CT for characterising nodules in the cirrhotic liver: a retrospective study
}

Shalini Thapar Laroia ${ }^{*}$ (D), Komal Yadav', Senthil Kumar², Archana Rastogi ${ }^{3}$, Guresh Kumar ${ }^{4}$ and Shiv Kumar Sarin ${ }^{5}$

\begin{abstract}
Background: There is limited scientific evidence on the potential of spectral computed tomography (SCT) for differentiation of nodules in the cirrhotic liver. We aimed to assess SCT-generated material density (MD) parameters for nodule characterisation in cirrhosis.

Methods: Dynamic dual-energy SCT scans of cirrhotic patients performed over 3 years were retrospectively reviewed. They were classified as hepatocellular carcinoma (HCC), regenerative or indeterminate, according to the European Association for the Study of the Liver criteria. MD maps were generated to calculate the area under the curve (AUC) and cutoff values to discriminate these nodules in the hepatic arterial phase (HAP) and portal venous phase (PVP). MD maps included iodine concentration density (ICD) of the liver and nodule, lesion-to-normal liver ICD ratio (LNR) and difference in nodule ICD between HAP and PVP.

Results: Three hundred thirty nodules belonging to 300 patients (age $53.0 \pm 12.7$ years, mean \pm standard deviation) were analysed at SCT (size $2.3 \pm 0.8 \mathrm{~cm}$, mean \pm SD). One hundred thirty-three (40.3\%) nodules were classified as HCC, 147 (44.5\%) as regenerative and 50 (15.2\%) as indeterminate. On histopathology, 136 (41.2\%) nodules were classified as HCC, 183 (55.5\%) as regenerative and 11 (3.3\%) as dysplastic. All MD parameters on HAP and the nodule difference in ICD could discriminate pathologically proven HCC or potentially malignant nodules from regenerative nodules $(p<0.001$ ). The AUC was $82.4 \%$ with a cutoff $>15.5 \mathrm{mg} / \mathrm{mL}$ for nodule ICD, $81.3 \%>1.8$ for LNR-HAP and $81.3 \%$ for difference in ICD $>3.5 \mathrm{mg} / \mathrm{mL}$.
\end{abstract}

Conclusion: SCT-generated MD parameters are viable diagnostic tools for differentiating malignant or potentially malignant from benign nodules in the cirrhotic liver.

Keywords: Carcinoma (hepatocellular), lodine, Liver cirrhosis, Liver neoplasms, Tomography (x-ray, computed)

\footnotetext{
* Correspondence: thaparshalini@gmail.com

'Department of Radiology, Institute of Liver and Biliary Sciences, Sector D-1,

Vasant Kunj, New Delhi 110070, India

Full list of author information is available at the end of the article
}

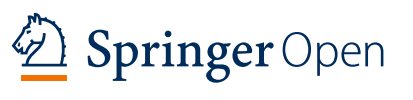

(c) The Author(s). 2021 Open Access This article is licensed under a Creative Commons Attribution 4.0 International License, which permits use, sharing, adaptation, distribution and reproduction in any medium or format, as long as you give appropriate credit to the original author(s) and the source, provide a link to the Creative Commons licence, and indicate if changes were made. The images or other third party material in this article are included in the article's Creative Commons licence, unless indicated otherwise in a credit line to the material. If material is not included in the article's Creative Commons licence and your intended use is not permitted by statutory regulation or exceeds the permitted use, you will need to obtain permission directly from the copyright holder. To view a copy of this licence, visit http://creativecommons.org/licenses/by/4.0/. 


\section{Key points}

- Spectral computed tomography-generated material density values provide a viable quantitative imaging tool.

- Material density parameters can discriminate malignant from benign cirrhotic nodules.

- This model offers an add-on diagnostic tool for the characterisation of cirrhotic nodules.

\section{Background}

End-stage nodular cirrhosis is the final pathological entity of many different progressive liver diseases $[1,2]$. Cirrhotic nodules can be classified as benign (regenerative), indeterminate (potentially malignant/dysplastic) or malignant (hepatocellular carcinoma, HCC) [3]. Regenerative nodules are considered 'benign' due to a lack of phenotypically abnormal cells but are known to contain genomically atypical cells [4-6]. Dysplastic nodules containing both normal and dysplastic hepatocytes are considered precursors to HCC. Inconclusive imaging features such as arterial hypervascularity without subsequent washout or hypodensity on delayed phase without overt arterial enhancement with nodule size $>1 \mathrm{~cm}$ may be used to identify indeterminate nodules at computed tomography (CT) [7-13].

The main radiological system to classify cirrhotic nodules at CT and MRI is the Liver Imaging Reporting and Data System (LI-RADS) [14]. According to the LIRADS, all cirrhotic nodules have the potential to be HCC, ranging from least likely, namely LI-RADS category 1 (definitely benign), to most, LI-RADS category 5 (definitely malignant) [14]. Mid-spectrum categories such as LI-RADS 3 or 4 fall into the indeterminate zone of diagnostic suspicion, i.e., they do not represent definite HCC nor benign regenerative nodules [15]. Such lesions, especially nodules between 1 and $2 \mathrm{~cm}$ in size, are often found to be dysplastic or well-differentiated HCC on pathological examination [16-19]. The most recent LI-RADS-based guidelines have shown a sensitivity of $89.6 \%$, a specificity of $81.2 \%$ and an overall diagnostic accuracy of $88.0 \%$ for HCC lesions $>2 \mathrm{~cm}$ [20].

The advent of spectral computed tomography (SCT) and its ability to generate synchronous datasets of polychromatic and monochromatic images with material density (MD) maps has enabled radiologists to experiment beyond the conventional enhancement patternbased algorithms, which visually assess contrast uptake, retention and washout [21-25]. The most recent upgrades in CT hardware and software allowed the use of SCT for tissue characterisation using MD maps [26]. In fact, at SCT, images from two distinct $\mathrm{x}$-ray spectra at $70-80 \mathrm{kVp}$ (low energy) and 120-140 kVp (high energy) can be exploited to visualise hypervascular lesions with better conspicuity on MD datasets [25, 27, 28]. MD images are used to calculate the iodine concentration density (ICD) of the lesion, measured in milligrams per milliliter along with other parameters [29-32].

Most SCT liver studies have investigated the diagnosis and differentiation of $\mathrm{HCC}$ from benign hypervascular lesions such as haemangioma, fibronodular hyperplasia or angiomyolipoma in noncirrhotic populations [33-36]. However, there is a lack in existing scientific knowledge regarding the potential of SCT for the overall differentiation of nodules in the cirrhotic liver [37-39].

Thus, the aim of this study was to assess the diagnostic performance of SCT for the discrimination of malignant (HCC), potentially malignant (indeterminate) and benign (regenerative) nodules in cirrhosis patients.

\section{Methods}

\section{Population}

This single-centre retrospective study was approved by the institutional ethics board, and the requirement for informed consent was waived. We screened SCT scans of 380 cirrhotic patients performed from January 2016 to June 2019. SCT scans were obtained by searching the hospital and radiology database for the cirrhotic population who underwent pre-transplant and surveillance CT scans. For inclusion in the study, patients who underwent pre-transplant $\mathrm{CT}$, as per institute protocol $(n=$ $300)$, and those who were found to have liver nodules on $\mathrm{CT}$, who subsequently underwent biopsy $(n=20)$, were included. Patients with identifiable nodules on SCT who did not undergo liver transplantation or follow-up with biopsy $(n=80)$ were excluded.

A total of 330 nodules from 300 selected SCT studies were independently evaluated by two observers with more than 4 years of experience in liver imaging. Conflicting observations between the two reviewers were reevaluated at a consensus meeting, and a final decision was taken in the presence of a third reviewer. The workflow of the study is shown in Fig. 1.

\section{SCT protocol}

Scans that were performed as a triple-phase study on the single-source, dual-energy, 64-slice CT scanner (Discovery CT 750 HD, General Electric Healthcare, USA) with fast $\mathrm{kVp}$ switching between 80 and $140 \mathrm{kVp}$ were included. Scanning protocol and technique are summarised in Table 1.

\section{Image analysis}

The polychromatic image sets with $120 \mathrm{kVp}$ photon energy, which are analogous to the conventional CT images, were used to classify cirrhotic nodules into HCC, indeterminate and regenerative based on enhancement pattern of lesions on hepatic arterial phase (HAP) and 


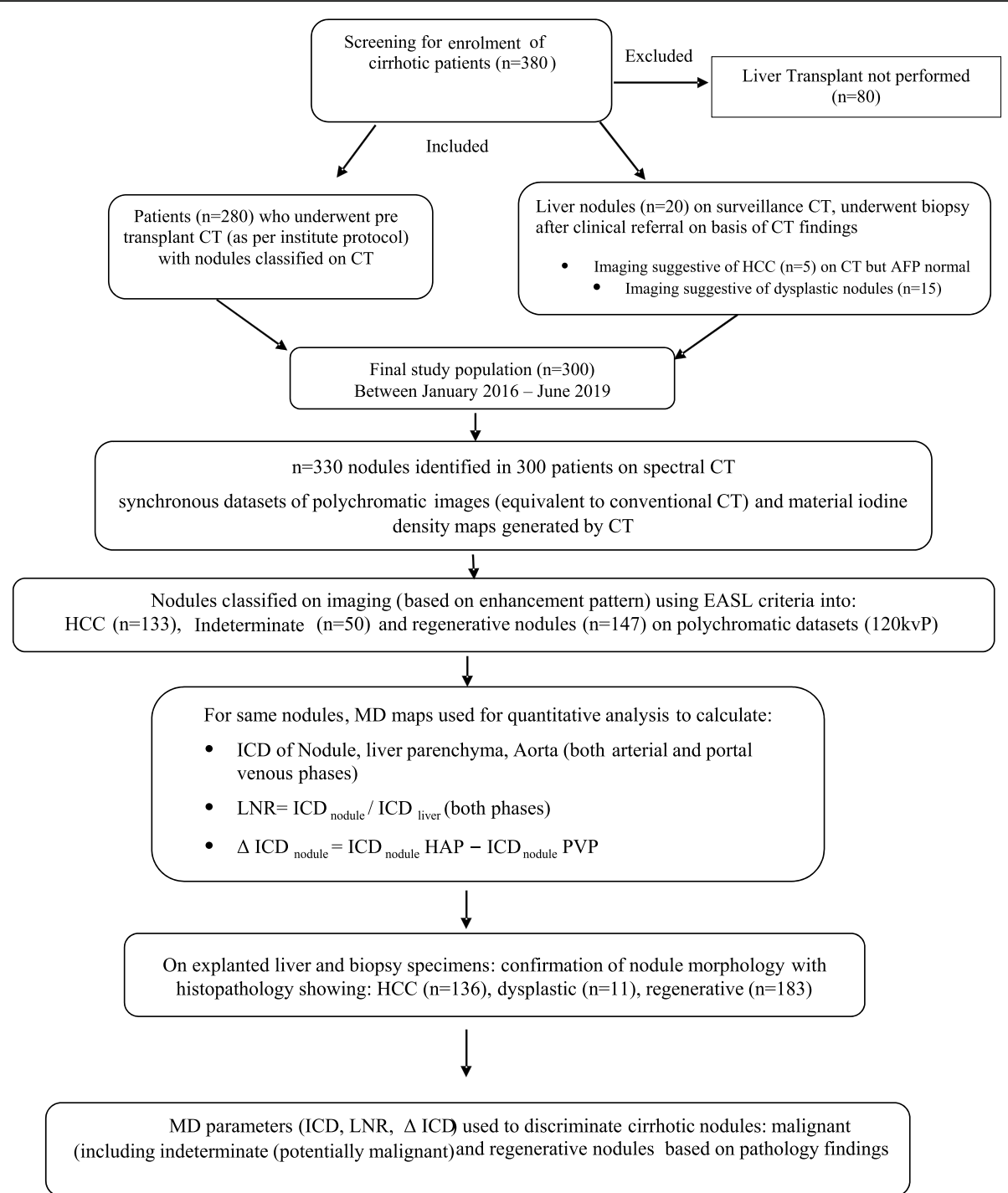

Fig. 1 Flowchart of the study design and workflow. AFP Alpha-fetoprotein, CT Computed tomography, EASL European Association for the Study of the Liver, HCC Hepatocellular carcinoma, ICD lodine concentration density. $L N R=I C D_{\text {nodule }} / I C D_{\text {liver, }}$ ICD difference of nodule $\left(\triangle I C D_{\text {nodule }}\right)=$ $I C D_{\text {nodule }}$ HAP minus ICD nodule PVP

portal venous phase (PVP) (Fig. 2). Nodules with HAP hypervascularity and subsequent washout on PVP or delayed phase were classified as HCC [40]. Nodules that did not show classical features of HCC (neither hypervascular nor displaying washout) were classified as 'regenerative' (non-HCC by EASL criterion) (Fig. 3) [17]. Since we excluded all other liver lesions at the beginning of the study, benign lesions were synonymous for regenerative nodules for this study. Nodules with ambiguous enhancement, such as isolated arterial hypervascularity or exhibition of washout or capsule formation on PVP without arterial enhancement, were grouped as 'indeterminate' nodules [41].

The MD images generated by SCT were viewed and analysed with material decomposition and projection- based software on the workstation (CTAW software 4.4, General Electric Healthcare, USA), with a standard softtissue display window (preset at $40 \mathrm{HU}$ and width 400 $\mathrm{HU})$. Images were reviewed at a standard reconstruction kernel on HAP and PVP.

Iodine density of the nodule ( $\left.\mathrm{ICD}_{\text {nodule }}\right)$, liver parenchyma $\left(\mathrm{ICD}_{\text {liver }}\right)$ and aorta $\left(\mathrm{ICD}_{\text {aorta }}\right)$ were measured in milligrams per milliliter on HAP and PVP with the help of three discrete circular regions of interest (ROIs) of equal area, size and shape, carefully placed in the maximum enhancing portion of each structure, at the same level in the abdomen, as shown in Fig. 2. The average number of pixels in each ROI was 400 (range 310-560). Three parameters were calculated using the above values: lesion-to-normal liver ratio $\left(\mathrm{LNR}=\mathrm{ICD}_{\text {nodule }} /\right.$ 
Table 1 Computed tomography protocol

\begin{tabular}{ll}
\hline Mode & $\begin{array}{l}\text { Supine position } \\
\text { Spectral imaging mode } \\
\text { Fast tube voltage switching between } \mathbf{8 0} \text { and } \mathbf{1 4 0} \mathbf{k V} \mathbf{p} \\
\text { Craniocaudal direction }\end{array}$ \\
\hline $\begin{array}{ll}\text { Collimation thickness } \\
\text { Slice thickness }\end{array}$ & $0.625 \mathrm{~mm}$ (64 detectors) \\
Reconstruction parameters & $5 \mathrm{~mm}$ \\
Tube current & $1-\mathrm{mm}$ thickness, 1-mm interval \\
Rotation speed & $600 \mathrm{~mA}$ \\
Helical pitch & $0.6 \mathrm{~s}$ \\
Reconstruction & 0.983 \\
Contrast agent & Adaptive statistical iterative reconstruction (ASIR) \\
Contrast agent dose and rate & lomeprol, Bracco, Konstanz, Germany (400 mgl/mL) \\
Saline bolus and rate & $1.5 \mathrm{~mL} / \mathrm{kg}$ body weight, at the rate of $4 \mathrm{~mL} / \mathrm{s}$ \\
Scan delay & $50 \mathrm{~mL}$ at the rate of $4 \mathrm{~mL} / \mathrm{s}$
\end{tabular}

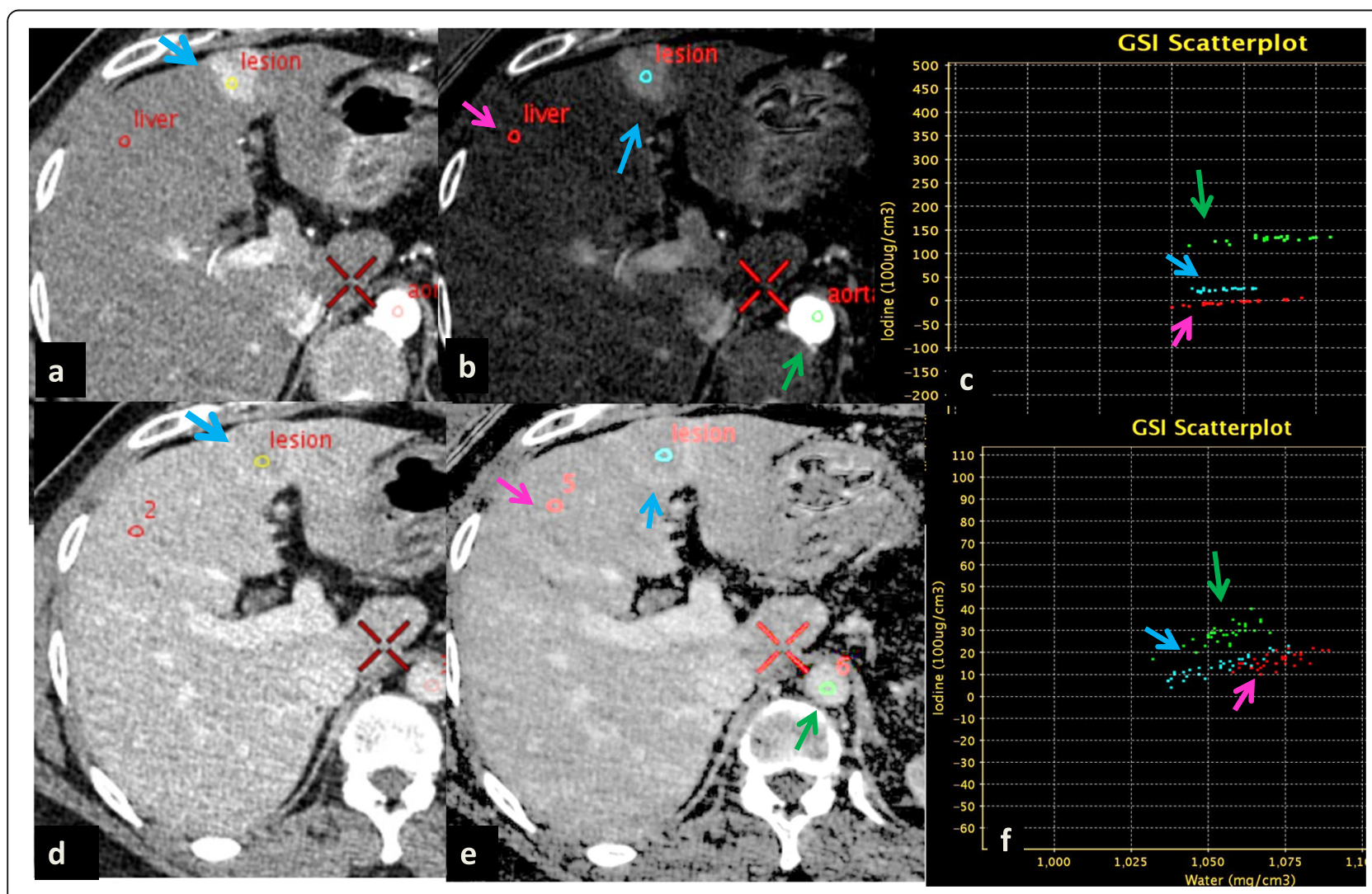

Fig. 2 Spectral computed tomography (SCT) of a patient with cirrhosis and hepatocellular carcinoma depicting polychromatic, material density (MD) map, and scatter plots. a Arterial phase axial polychromatic image showing well-defined subcapsular hypervascular lesion (HCC), measuring $2.4 \mathrm{~cm}$ in segment IV (blue arrow). b lodine density map showing ROI (blue circle) within lesion to calculate ICD nodule HAP (blue arrow), ROI in the liver (red circle) to measure ICD liver HAP (pink arrow), and ICDaorta (green arrow). c Scatter plot depicting the highest iodine density value of the aorta (green arrow), lesion iodine density (blue arrow) less than the aorta but more than the background liver (pink arrow). $\mathbf{d}$ Portal venous phase polychromatic image showing segment IV lesion depicting washout (yellow circle) with capsular enhancement (blue arrow). e Corresponding iodine density map showing ROI within lesion (blue circle) to calculate ICD nodule PVP, ICD aorta PVP (green circle), and ICD liver PVP (pink circle). f Scatter plot depicting the highest ICD aorta PVP (green arrow), ICD nodule PVP (blue arrow) showing a decreasing trend of iodine density compared to the background liver (pink arrow) 


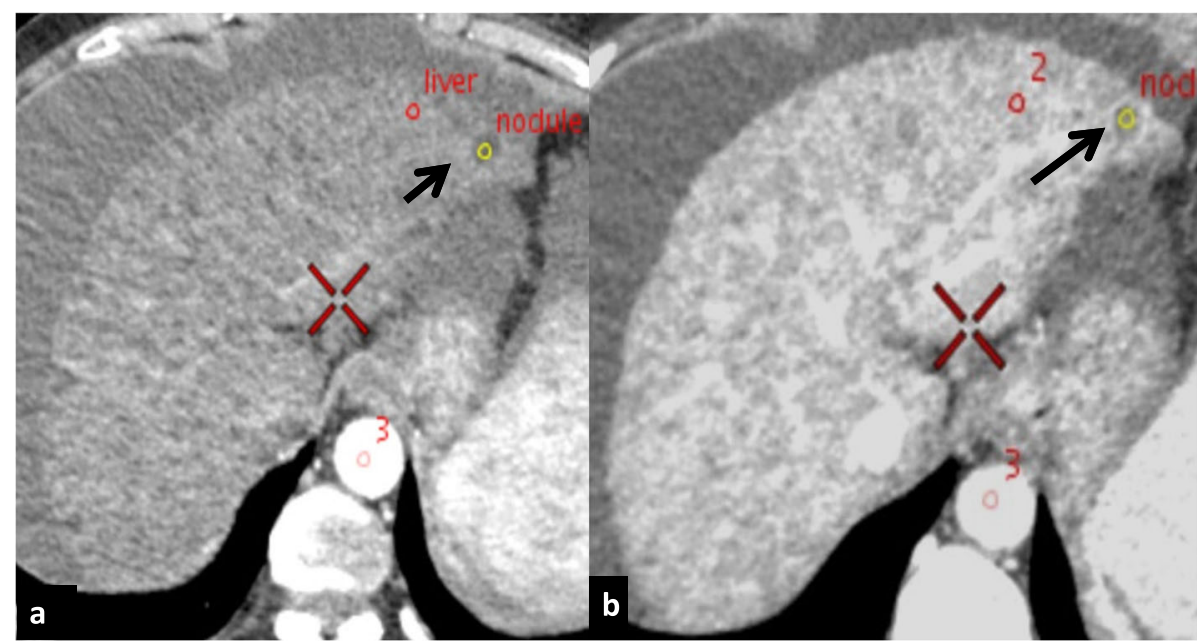

Fig. 3 Computed tomography of a patient with underlying cirrhosis depicting 'regenerative' nodule. a Polychromatic axial image on HAP showing a well-defined subcapsular non-enhancing lesion (yellow ROI), in segment II (black arrow). b Polychromatic PVP image shows persistent non-enhancement of the same lesion (yellow ROI) in segment II (black arrow)

$\left.\mathrm{ICD}_{\text {liver }}\right)$, normalised iodine concentration $(\mathrm{NIC}=\mathrm{ICD}$ nodule $\left./ \mathrm{ICD}_{\text {aorta }}\right)$ and difference in ICD $\left(\triangle \mathrm{ICD}=\mathrm{ICD}_{\text {nodule }}\right.$ HAP - ICD nodule PVP). The NIC was measured as a baseline reference for optimum enhancement, to minimise variations among patients.
For MD parameter analysis, nodules were organised into two broad groups: malignant (HCC), also including potentially malignant (indeterminate) nodules, versus benign (regenerative) nodules owing to the limitation of pathological confirmation of dysplastic nodules and the

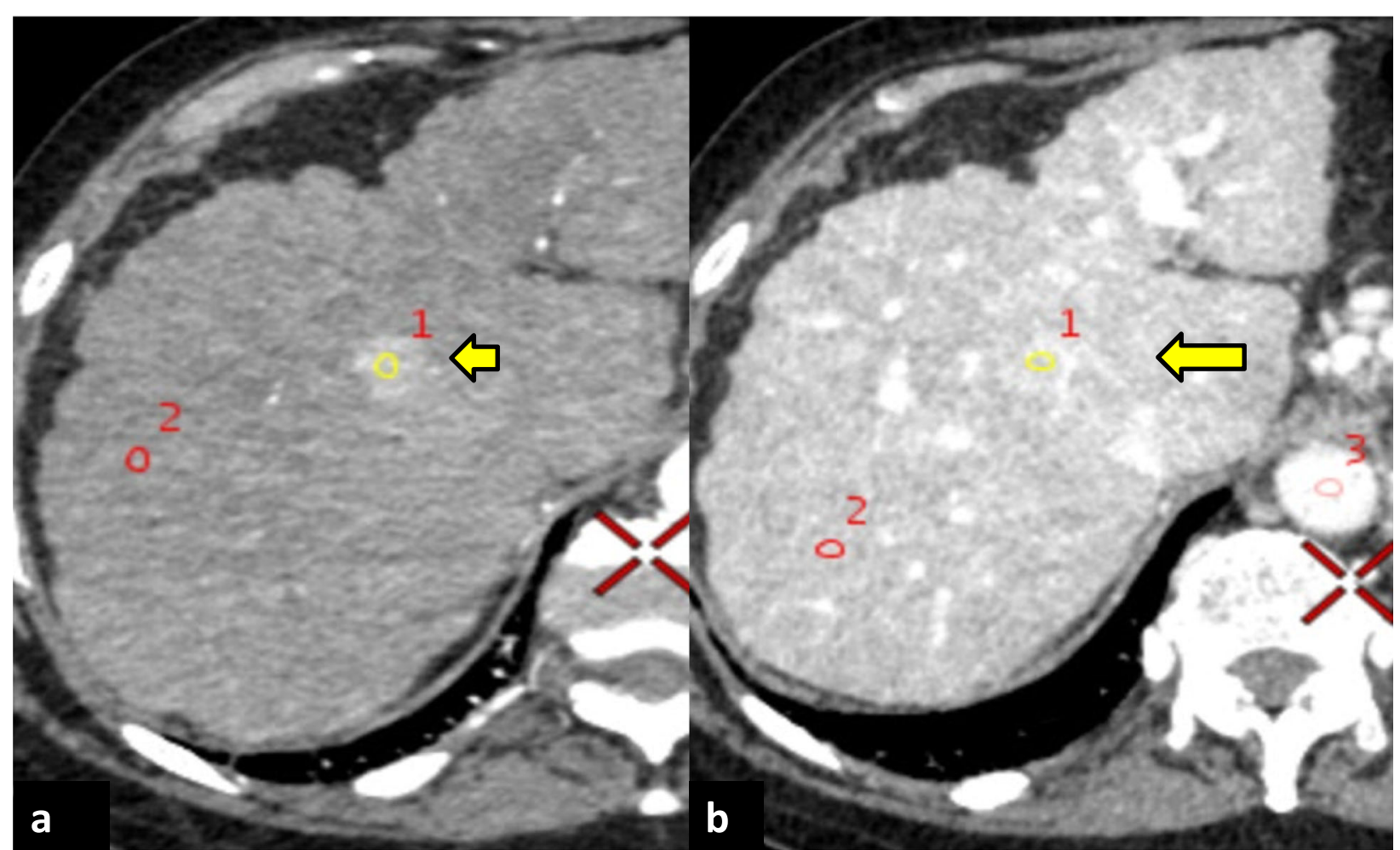

Fig. 4 Computed tomography of a patient with underlying cirrhosis depicting an 'indeterminate' nodule. a Polychromatic axial image on HAP depicting a hypervascular nodule (yellow ROI), in segment VIII (yellow arrow). b Polychromatic axial image on PVP of the same nodule shows persistent enhancement without overt washout (yellow ROI) in segment VIII (yellow arrow) 
significance of their stepwise progression to frank HCC [8, 10, 11] (Fig. 4).

Serum alpha-fetoprotein (AFP) values were recorded for all patients at the time the scan was performed, with observer blinding and used for statistical and comparative data analysis. Histopathology results of explant liver specimens (310 nodules) and nodule biopsy (20 nodules) were used as a reference standard.

\section{Histopathological analysis}

Percutaneous ultrasound-guided liver biopsy was performed using an 18-gauge cutting needle. Explant and biopsy specimens were routinely processed for systematic histological evaluation. All biopsies were read by a liver pathologist with 15 years of experience who was blinded to imaging results.

Regenerative nodules were classified on basis of features of a hyperplastic or a hepatocellular nodule at low magnification, without distinct cytoarchitectural features from the extralesional cirrhotic background, intralesional 2 cell-thick hepatocyte plates and unconnected lesion portal tracts [8]. Dysplastic nodules were characterised by architectural abnormalities such as 2 or
3 cell-thick hepatocyte plates, low-grade cytological atypia, nuclear crowding, inconstant detection of map-like clonal growth or nodule-in-nodule appearance, and inconstant increase in the number of unpaired arterioles which was confirmed by smooth muscle actin immunostaining. Progressive sinusoidal capillarisation was detected by CD34 immunostaining. Distinction from welldifferentiated HCC is known to be challenging $[9-11,16]$. A diagnosis of HCC was finalised on seeing architectural abnormalities such as nuclear crowding, three or more cell-thick hepatocyte plates, relative cell monomorphism, presence of multiple microacinar structures with or without bile plugs, an abnormally high number of muscularised unpaired arterioles, capillarised vessels and infiltration of the portal tract, fibrous septa, or veins by single hepatocytes $[9-11,16]$.

\section{Statistical analysis}

Continuous data were presented as mean \pm standard deviation (SD) or median with interquartile range (IQR) according to data normality. The comparison was made using a one-way analysis of variance (ANOVA) test, followed by a post hoc test by the Bonferroni method.

Table 2 Characteristics of patients with CT diagnosis of liver nodules and histopathology correlation

\begin{tabular}{|c|c|c|c|c|c|}
\hline Characteristics & $\begin{array}{l}\text { Total nodules } \\
330\end{array}$ & $\begin{array}{l}\text { HCC on CT } 133 \\
(40.3 \%)\end{array}$ & $\begin{array}{l}\text { Indeterminate on CT } \\
50 \\
(15.2 \%)\end{array}$ & $\begin{array}{l}\text { Regenerative on CT } \\
147 \\
(44.5 \%)\end{array}$ & $p$-value \\
\hline Age (years, mean $\pm S D$ ) & $53.2 \pm 12.7$ & $58.6 \pm 11.6$ & $56.7 \pm 10$ & $47.1 \pm 11.8$ & $<0.001$ \\
\hline Gender (male/female) & $266 / 64$ & $108 / 25$ & $38 / 12$ & $120 / 27$ & 0.667 \\
\hline $\log$ AFP $(n g / m L$, mean \pm SD) & $2.63 \pm 3.1$ & $3.5 \pm 2.3$ & $3.01 \pm 2.4$ & $1.7 \pm 1.1$ & $<0.001$ \\
\hline Nodule size (cm, median (IQR)) & $1.7(1.1-2.1)$ & $2.1(1.9-5.0)$ & $1.4(1.2-1.6)$ & $1.2(1-1.8)$ & $<0.001$ \\
\hline Increased AFP (> $8.5 \mathrm{ng} / \mathrm{mL})(\%)$ & $138(41.8)$ & $84(63.1)$ & $31(62)$ & $23(15.6)$ & $<0.001$ \\
\hline \multicolumn{6}{|c|}{ Nodules classified according to size (largest diameter) on CT } \\
\hline$<1 \mathrm{~cm}$ (\% of total nodules) & $29(8.8)$ & $0(0)$ & $2(4)$ & $27(18.5)$ & $<0.001$ \\
\hline $1-2 \mathrm{~cm}$ (\% of total nodules ) & $198(60)$ & $48(36)$ & $44(88)$ & $106(72)$ & \\
\hline$>2 \mathrm{~cm}$ (\% of total nodules) & $103(31.2)$ & $85(63.9)$ & $4(8)$ & $14(9.5)$ & \\
\hline \multicolumn{6}{|l|}{ CT histopathology correlation } \\
\hline Histopathology classification (\%) & & $\begin{array}{r}\text { HCC } \\
136(41.2 \%)\end{array}$ & $\begin{array}{c}\text { Dysplastic } \\
11(3.3 \%)\end{array}$ & & $\begin{array}{r}\text { Regenerative } \\
183(55.5 \%)\end{array}$ \\
\hline True positive on $C T$ & & 129 & 7 & & 141 \\
\hline True negatives on $C T$ & & 190 & 276 & & 141 \\
\hline False positive on $\mathrm{CT}$ & & 4 & 43 & & 6 \\
\hline False negative on $\mathrm{CT}$ & & 7 & 4 & & 42 \\
\hline Sensitivity \% (95\% Cl) & & $94.9(89.8-97.5)$ & $63.6(35.4-84.8)$ & & $77.0(70.4-82.5)$ \\
\hline Specificity \% (95\% Cl) & & $97.9(94.8-99.2)$ & $86.5(82.3-89.8)$ & & $95.9(91.4-98.1)$ \\
\hline PPV \% (95\% CI) & & $96.9(92.5-98.8)$ & $14(6.9-6.2)$ & & $95.9(91.4-98.1)$ \\
\hline NPV \% (95\% Cl) & & 96.5 (92.9-98.3) & $98.6(96.4-99.44)$ & & $77.1(70.4-82.5)$ \\
\hline Accuracy \% (95\% Cl) & & $96.7(94.1-98.1)$ & $85.8(81.6-89.1)$ & & $85.5(81.2-88.9)$ \\
\hline
\end{tabular}

AFP Alpha-fetoprotein, CT Computed tomography, CI Confidence interval, IQR Interquartile range, SD Standard deviation, NPV Negative predictive value, PPV Positive predictive value 
Categorical data were reported as numbers and frequencies (\%) and compared by using the $\chi^{2}$ test or Fisher exact test as applicable. The agreement between two observers was assessed using kappa $(\kappa)$ statistics.

The comparison between malignant or potentially malignant ( $\mathrm{HCC}$ and indeterminate) and benign (regenerative) nodules for comparing and analysing the significance of MD parameters on SCT was computed using the Mann-Whitney $U$ test or independent $t$-test as appropriate. Sensitivity, specificity, positive predictive values and negative predictive values were calculated with their 95\% confidence intervals (CI), according to the binomial distribution. The area under the curve (AUC) at receiver operating characteristic (ROC) analysis was also calculated. The quantification of effect (odds ratio, OR) was based on the nominal logistic regression where imaging discrimination of more than two nodules, i.e., HCC, indeterminate/dysplastic or regenerative, was calculated. The logistic regression analysis was used to quantify the effect and to derive cutoff values for malignant or potentially malignant and benign nodules. All analyses were performed using SPSS statistical software (version 22, IBM, USA). A $p$ value less than 0.05 was considered to indicate statistical significance.

\section{Results}

The mean size of 330 analysed nodules was $2.3 \pm 0.8$ $\mathrm{cm}$. Such 330 nodules were found in 300 cirrhotic patients of which 280 were pre-transplant candidates and 20 were under surveillance. The majority of patients ( $n$ $=266 ; 89 \%$ ) were men; mean patients' age was $53.2 \pm$ 12.7 years. The interobserver agreement between the two radiologists gave a $\kappa$ value of 0.95 . All details of imaging diagnosis and pathology correlation are shown in Table 2 and Supplementary Table 3. Enhancement characteristics of nodules are detailed in Table 3.

On HAP, 124/330 (38\%) nodules were hypervascular with 98/124 (79\%) demonstrating subsequent washout, characteristic of HCC (Table 3). Mild enhancement on
HAP was present in $47 / 330$ (14\%) nodules with $27 / 47$ (57\%) of these subsequently showing washout. These were also classified as HCC (Table 3). Some other nodules, 24/124 (19\%) which showed hypervascularity, but inadequate washout, were categorised as indeterminate nodules.

A total of 159/330 (48\%) nodules were non-enhancing on HAP, 140/159 (88\%) of which showed consistent hypoattenuation on PVP as well. Based on this pattern, these were classified as regenerative nodules (Table 3).

A total of 166 nodules demonstrated contrast washout. Most of them, 125/166 (75\%), were classified as HCC; few, 40/166 (24\%), were diagnosed as indeterminate, due to the absence of classical arterial hypervascularity; and one nodule was classified as regenerative (1\%) (Table 3). The details of enhancement, with reference to nodule size, have been enumerated in Supplementary Table 1.

A total of 133/330 (40.3\%) nodules were classified as HCC, of which 129 were confirmed on pathology. Among the remaining false-positive HCC's, one nodule was dysplastic and three regenerative. Thus, for diagnosis of HCC, CT demonstrated a sensitivity of $94.9 \%$ (95\% CI $89.8-97.5 \%)$ and a PPV of 96.9\% (95\% CI 92.5-98.8) (Table 2).

A total of $147 / 330$ (44.5\%) nodules were classified as 'regenerative' on CT whereas 183/330 (55.5\%) nodules were confirmed 'regenerative' on pathology (Table 2). On CT, 37 biopsy-proven regenerative nodules (measuring $1-2 \mathrm{~cm}$ ) and two nodules (measuring $<1 \mathrm{~cm}$ ) were categorised as 'indeterminate'. Three nodules (size 1-2 $\mathrm{cm})$ were also inadvertently classified as HCC. CT thus demonstrated a sensitivity of $77 \%$ (95\% CI 70.4-82.5\%) and PPV of 95.9\% (95\% CI 91.4-98.1\%) for diagnosis of regenerative nodules.

CT observations correctly classified 97\% (95\% CI 94.1-98.1\%) of HCC and $85.5 \%$ (95\% CI $81.2-88.9 \%$ ) of regenerative nodules at pathology (Table 2).

A total of 50/330 (15.2\%) lesions were classified as indeterminate nodules on CT; on pathology, 39/50 (78\%) of

Table 3 Enhancement pattern of nodules on computed tomography

\begin{tabular}{|c|c|c|c|c|c|c|}
\hline \multicolumn{2}{|c|}{ Enhancement pattern on different phases } & \multirow{2}{*}{$\begin{array}{r}\text { Total nodules } \mathbf{3 3 0} \\
124 \\
(37.6)\end{array}$} & \multirow{2}{*}{$\begin{array}{r}\text { HCC } 133 \\
98 \\
(73.7)\end{array}$} & \multirow{2}{*}{$\begin{array}{r}\text { Indeterminate } \mathbf{5 0} \\
24 \\
(48)\end{array}$} & \multirow{2}{*}{$\begin{array}{r}\text { Regenerative } \mathbf{1 4 7} \\
2 \\
(1.4)\end{array}$} & \multirow{2}{*}{$\frac{\boldsymbol{p} \text {-value }}{<0.001}$} \\
\hline Hypervascular & $\begin{array}{l}\text { HAP } \\
(\%)\end{array}$ & & & & & \\
\hline \multirow[t]{2}{*}{ Hypoattenuating } & $\begin{array}{l}\text { HAP } \\
(\%)\end{array}$ & $\begin{array}{r}159 \\
(48.2)\end{array}$ & $\begin{array}{r}8 \\
(6)\end{array}$ & $\begin{array}{r}11 \\
(22)\end{array}$ & $\begin{array}{r}140 \\
(95.2)\end{array}$ & $<0.001$ \\
\hline & $\begin{array}{r}\text { PVP } \\
(\%)\end{array}$ & $\begin{array}{r}320 \\
(96.9)\end{array}$ & $\begin{array}{r}131 \\
(98.5)\end{array}$ & $\begin{array}{r}46 \\
(92)\end{array}$ & $\begin{array}{r}143 \\
(97.3)\end{array}$ & 0.084 \\
\hline \multirow[t]{2}{*}{ Mild or subtle enhancement } & $\begin{array}{l}\text { HAP } \\
(\%)\end{array}$ & $\begin{array}{r}47 \\
(14.2)\end{array}$ & $\begin{array}{r}27 \\
(20.3)\end{array}$ & $\begin{array}{r}15 \\
(30)\end{array}$ & $\begin{array}{r}5 \\
(3.4)\end{array}$ & $<0.001$ \\
\hline & $\begin{array}{l}\text { PVP } \\
(\%)\end{array}$ & $\begin{array}{l}10 \\
(3)\end{array}$ & $\begin{array}{r}2 \\
(1.5)\end{array}$ & $\begin{array}{r}4 \\
(8)\end{array}$ & $\begin{array}{r}4 \\
(2.7)\end{array}$ & 0.084 \\
\hline Washout present & $\begin{array}{r}n \\
(\%)\end{array}$ & $\begin{array}{r}166 \\
(50.3)\end{array}$ & $\begin{array}{r}125 \\
(93.9)\end{array}$ & $\begin{array}{r}40 \\
(80)\end{array}$ & $\begin{array}{r}1 \\
(0.7)\end{array}$ & $<0.001$ \\
\hline
\end{tabular}


Table 4 Material density parameters of malignant and benign nodules on spectral computed tomography

\begin{tabular}{|c|c|c|c|}
\hline MD parameters & Malignant (HCC and indeterminate) 147 & Benign (regenerative) 183 & $p$ value \\
\hline \multicolumn{4}{|l|}{ On HAP } \\
\hline ICD nodule $(\mathrm{mg} / \mathrm{mL})$ & $19(16-25)$ & $9(4-15)$ & $<0.001$ \\
\hline LNR & $2.8(1.8-5.5)$ & $0.8(0.5-1.8)$ & $<0.001$ \\
\hline $\mathrm{NIC}(\mathrm{mg} / \mathrm{mL})$ & $0.2(0.1-0.2)$ & $0.1(0.04-0.1)$ & $<0.001$ \\
\hline$I C D_{\text {liver }}(\mathrm{mg} / \mathrm{mL})$ & $6(3-11)$ & $8(4-12)$ & 0.002 \\
\hline \multicolumn{4}{|l|}{ On PVP } \\
\hline $\mathrm{ICD}_{\text {nodule }}(\mathrm{mg} / \mathrm{mL})$ & $10(6-14)$ & $13(8-19)$ & 0.004 \\
\hline LNR & $0.6(0.4-0.8)$ & $0.6(0.4-0.8)$ & 0.869 \\
\hline $\mathrm{NIC}(\mathrm{mg} / \mathrm{mL})$ & $0.2(0.1-0.4)$ & $0.3(0.2-0.5)$ & 0.003 \\
\hline$I C D_{\text {liver }}(\mathrm{mg} / \mathrm{mL})$ & $16(12-23)$ & $18(14-27)$ & 0.007 \\
\hline \multicolumn{4}{|l|}{ Difference between HAP and PVP } \\
\hline$\Delta \mathrm{ICD}$ nodule $(\mathrm{mg} / \mathrm{mL})$ Mean $\pm \mathrm{SD}$ & $8.3 \pm 11.2$ & $-2.9 \pm 9.5$ & $<0.001$ \\
\hline
\end{tabular}

All MD values are presented as median (interquartile range)

HAP Hepatic arterial phase, ICD lodine concentration density, LNR Lesion-to-normal liver iodine density (LNR = ICD lesion/ICD normal liver), MD Material density of iodine, NIC Normalised iodine concentration (NIC = ratio of $I C D_{\text {nodule }} / I C_{\text {aorta }}$ ), PVP Portal venous phase, SD Standard deviation, $\triangle I C D$ Delta iodine concentration $(\triangle \mathrm{ICD}=\mathrm{ICD}$ nodule $\mathrm{HAP}$ minus $\mathrm{ICD}$ nodule $\mathrm{PVP})$

these were regenerative and 4/50 (8\%) were $\mathrm{HCC}$, whereas only $5 / 50(10 \%)$ were dysplastic nodules (Table 3$)$. In comparison with pathology, CT demonstrated a sensitivity of $63.6 \%$ (95\% CI $35.4-84.8 \%$ ) and a PPV of $14 \%$ (95\% CI 6.9-6.2\%) for indeterminate nodules.

MD datasets from SCT were subsequently analysed to distinguish benign and malignant (including potentially malignant) cirrhotic nodules using MD parameters. They demonstrated an overall higher diagnostic sensitivity of 95.9\% (95\% CI 91.4-98.1\%), specificity of 77\% (95\% CI 70.4-82.5\%), PPV of 77\% (95\% CI 70.4-82.5\%) and NPV of $95.9 \%$ (95\% CI $91.4-98.2 \%$ ) and could correctly classify $282 / 330(85.5 \%, 95 \%$ CI $81.2-88.5 \%)$ 'malignant versus benign' lesions with respect to pathology (Table 4).

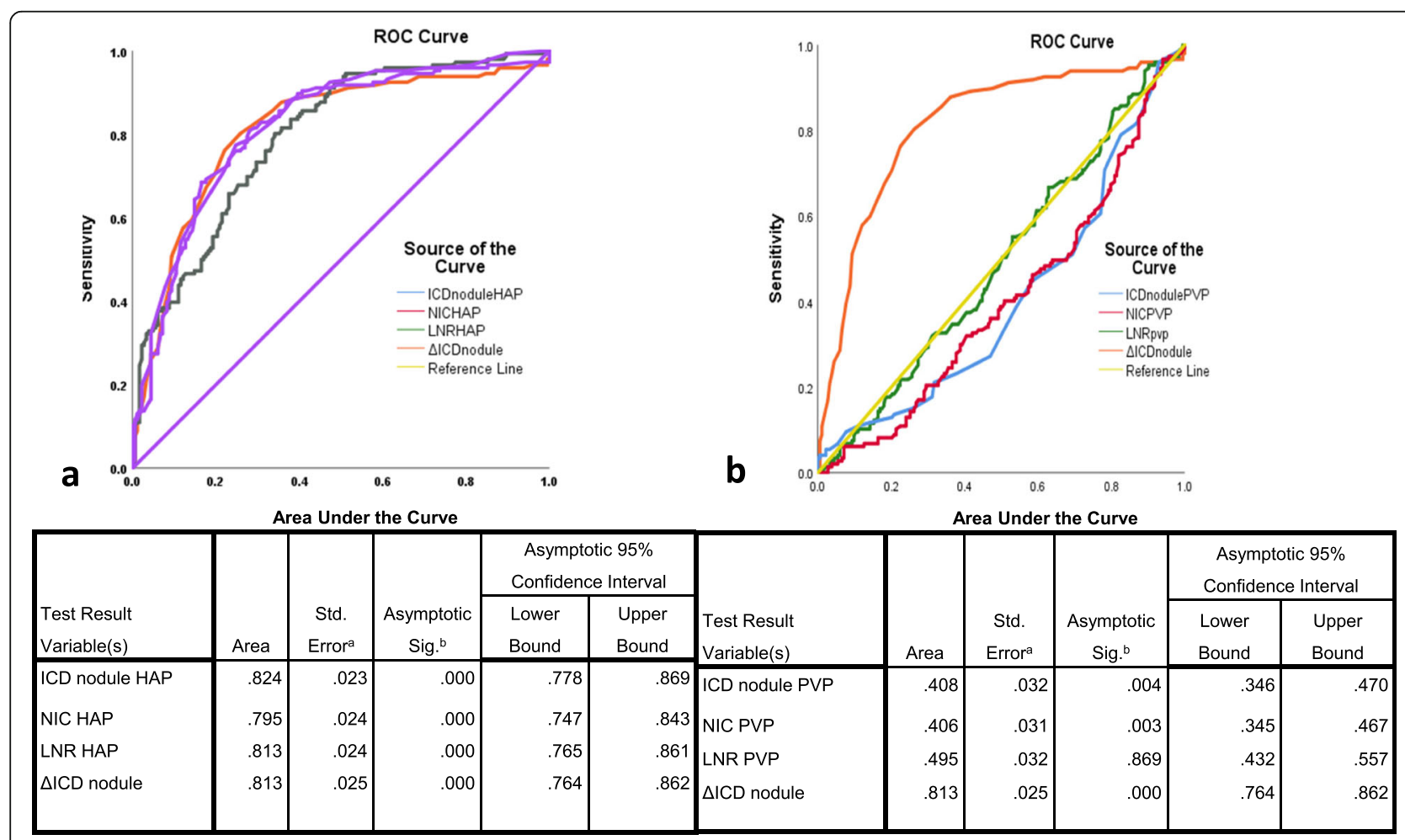

Fig. 5 Receiver operating curves of material density parameters with area under curve, sensitivity, and specificity of each parameter as tabulated below. a ROC curves plotted on HAP. b ROC curves plotted on PVP 
The Mann-Whitney test was applied between the two continuous data (Table 4) and revealed that median $\mathrm{ICD}_{\text {nodule }}$ HAP was higher $(p<0.001)$ for malignant 19 $\mathrm{mg} / \mathrm{mL}$ (IQR 16-25) versus benign $9 \mathrm{mg} / \mathrm{mL}$ (IQR 4-15 $\mathrm{mg} / \mathrm{mL})$ nodules. LNR was greater $(p<0.001)$ for malignant 2.8 (IQR 1.8-5.5) versus 0.8 (IQR 0.5-1.8) for benign nodules on HAP. NIC-HAP was higher $(p<0.001)$ for malignant $0.2 \mathrm{mg} / \mathrm{mL}$ (IQR $0.1-0.2$ ) versus $0.1 \mathrm{mg} / \mathrm{mL}$ (IQR 0.04-0.1) benign lesions, and NIC-PVP was lower $(p=0.001)$ for malignant $0.2 \mathrm{mg} / \mathrm{mL}$ (IQR 0.1-0.4) versus $0.3 \mathrm{mg} / \mathrm{mL}$ (IQR $0.2-0.5$ ) for benign nodules. $\mathrm{ICD}_{\text {nodule }}$ PVP was greater $(p=0.004)$ for benign $13 \mathrm{mg} / \mathrm{mL}$ (IQR $8-19 \mathrm{mg} / \mathrm{mL}$ ) versus $10 \mathrm{mg} / \mathrm{mL}$ (IQR 6-14 mg/mL) for malignant lesions. The $\triangle \mathrm{ICD}$ was significantly higher $(p<0.001)$ for malignant $(8.3 \pm 11.2 \mathrm{mg} / \mathrm{mL})$ than benign $(-2.9 \pm 9.5 \mathrm{mg} / \mathrm{mL})$ nodules (Table 4$)$.

All parameters except LNR-PVP which was the same 0.6 (IQR 0.4- 0.8) for both groups $(p=0.869)$ showed statistically significant values $(p<0.05)$ for nodule discrimination

For the discrimination of malignant nodules, ICD nodule HAP showed AUC 82.4\% (95\% CI 77.8-86.9\%), cutoff $\geq 15.5 \mathrm{mg} / \mathrm{mL}$ (sensitivity $77.4 \%$, specificity $75.3 \%, p<$ 0.001); LNR-HAP showed AUC 81.3\% (95 \% CI 76.5$86.1 \%$ ), cutoff $>1.80$ (sensitivity $76 \%$, specificity $75.3 \%, p$ $<0.001$ ) (Fig. 5). $\triangle \mathrm{ICD}$ demonstrated AUC 81.3\% (95\% CI $76.4-86.2 \%$ ) with cutoff $>3.5 \mathrm{mg} / \mathrm{mL}$ (sensitivity $76 \%$, specificity $78 \%, p<0.001$ ) (Fig. 5).

The MD parameters on PVP demonstrated AUC between 40 and $50 \%$, sensitivity $(50-58 \%)$ and specificity (50-60\%) as depicted in Fig. 5 along with the cutoff values (Supplementary Table 4).

MD parameters were analysed in both phases to define threshold values for differentiation of three cirrhotic nodules (Supplementary Figure 2) since pathology could not be considered as an absolute ground truth in case of dysplastic or regenerative nodules.

Nominal logistic regression showed that $\mathrm{ICD}_{\text {nodule }}$ HAP $>18.5 \mathrm{mg} / \mathrm{mL}$ with odds ratio (OR) 1.22 (95\% CI $1.17-1.27$ ) correctly classified HCC in $89 \%$ cases, $11.5-$ $18.5 \mathrm{mg} / \mathrm{mL}$ was consistent for dysplastic nodules with OR 1.17 (95\% CI 1.11-1.22) and values < $11.5 \mathrm{mg} / \mathrm{mL}$ correctly classified regenerative nodules in $74 \%$ with OR 1 (Supplementary Table 2).

\section{Discussion}

The main finding from our study is that MD parameters such as ICD nodule $_{\text {HAP, LNR-HAP, NIC-HAP, ICD nodule }}$ PVP, NIC-PVP, and $\triangle I C D$ provided adequate differentiation between the benign and malignant (including potentially malignant) nodules (all $p<0.05$ ). This finding established the feasibility of SCT for diagnosis and classification of cirrhotic nodules. Our results depicted an excellent agreement between the expected enhancement and perfusion pattern of malignant and benign nodules in the cirrhotic liver. We also observed that few MD parameters ( $\mathrm{ICD}_{\text {nodule }} \mathrm{HAP}, \mathrm{LNR}-\mathrm{HAP}, \triangle \mathrm{ICD}$, and NICHAP) showed higher diagnostic accuracy (all AUCs > $80 \%)$ than those previously reported $(70 \%)$ by nonspectral CT [42].

MD parameters on PVP were not as accurate as on HAP. We observed that LNR-PVP did not demonstrate significant demarcation between nodules. This could possibly be due to the unremarkable difference in contrast density of nodules as compared to the underlying liver on PVP, vis-a-vis the contrast divergence usually observed on HAP. Although this observation needs further validation, it implies that more weightage should be given to MD parameters on HAP than on PVP.

Pfeiffer et al. [37] have demonstrated the efficiency of LNR in both HAP and PVP as a better predictor than low (65) keV SCT or MRI for characterising HCC, and Gao et al. [43] demonstrated that LNR-HAP was the best parameter on MD maps to differentiate HCC from other liver nodules in cirrhotic patients.

Our analysis highlighted that $\mathrm{ICD}_{\text {nodule }}$ HAP is one of the best objective predictors for nodule differentiation. However, $\triangle \mathrm{ICD}$ appears to be the single most dependable marker, to discriminate cirrhotic nodules. This is likely since it incorporates data from both HAP and PVP, yields high diagnostic accuracy (AUC 81\%) and demonstrates distinct cutoff values for malignant versus benign nodules.

The unique capability of SCT to produce MD-based images which can be used to determine the composition of soft tissues has been extensively explored for oncological imaging [25, 44-47]. Matsui et. al [48] reported that liver nodules differentiate into cancer either via a de novo or a stepwise process where the intranodular hepatic vessels are gradually replaced by tumoural neovasculature. This change in nodule vascularity according to its morphological progression can be quantified by measuring their iodine absorption (K-edge $33.2 \mathrm{keV}$ of iodine makes it ideal for decomposition) which is an indirect measure of their vascularity [49]. Up to date, there are no clear-cut criteria (from EASL or LI-RADS) for the definition of dysplastic or regenerative nodules [40]. However, it is well known from previous studies that dysplastic and regenerative nodules are distinct entities that are visualised in the cirrhotic liver on different modalities [50]. MD values, which are primarily based on tissue iodine density, are exclusive to the inquired lesion and are independent of observer reading or interpretation. They have the potential to serve as non-invasive biomarkers for liver nodules in cirrhosis.

Cho et. al [51] showed that hepatocarcinogenesis is a time-dependant progression of benign to malignant nodules and this was illustrated in our study, by the 
presence of regenerative nodules in younger patients with more HCC nodules observed in the older population. Rizal et al. [52] demonstrated that cirrhosis, regardless of aetiology, is more prevalent in men, worldwide. This gender predilection was seen involving all three groups in our study, which was in line with these observations. The median nodule size and AFP also showed a significant increase from the regenerative to the malignant group. This trend indicated a concomitant increment in lesion size and AFP with evolution to malignant disease [53].

The majority of HCC's on CT were correctly classified in comparison to pathology. Only 3\% of the lesions, which demonstrated an atypical enhancement pattern, were misdiagnosed on imaging. These lesions measured $<1 \mathrm{~cm}$ on size, which was probably the reason for ambiguous enhancement.

Among the indeterminate nodules categorised on CT, only $10 \%$ were confirmed as dysplastic nodules on biopsy. We believe that this was because pathology could not adequately distinguish these nodules distinctly, as shown by previous studies, because low-grade dysplastic nodules either appear normal or show only minimal nuclear atypia and high-grade dysplastic nodules are extremely difficult to distinguish from well-differentiated HCC $[9,10]$. We believe that the rest of the $90 \%$ of the nodules classified as 'indeterminate' on SCT in our study were inadvertently categorised into regenerative or HCC groups on histopathology but could have actually represented dysplastic lesions.

Overall, CT showed a sensitivity and specificity for the diagnosis of malignant nodules of $95 \%$ and $77 \%$ and for regenerative nodules of $98 \%$ and $96 \%$, respectively, to be compared with a previously reported overall CT diagnostic accuracy (approximately 70.5\%) for characterisation of cirrhotic nodules [42].

Subsequently, MD parameters were applied to two nodule groups: malignant (comprising of $\mathrm{HCC}$ and potentially malignant/indeterminate lesions) and benign (regenerative) nodules, which demonstrated that all parameters could adequately discriminate the two categories with higher diagnostic accuracy of arterial phase parameters. Thus, SCT seems to yield the potential to be an optimum screening modality for dysplastic nodules and to distinguish them from regenerative nodules (Fig. 6). All nodules with $\mathrm{ICD}_{\text {nodule }} \mathrm{HAP}$ values $>11.5 \mathrm{mg} / \mathrm{mL}$ and

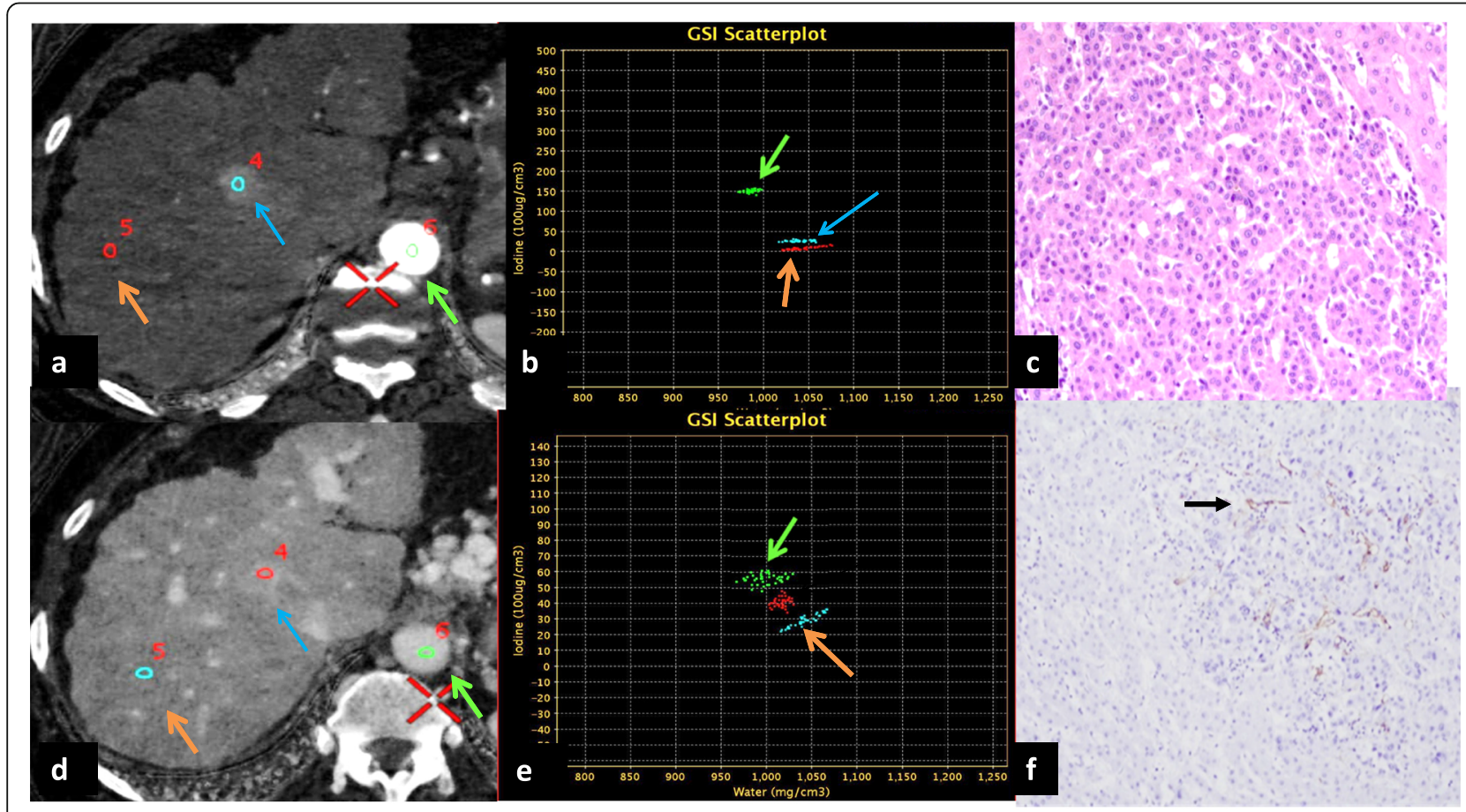

Fig. 6 Spectral computed tomography-based material density (MD) map (iodine only image) and scatter plots with histopathological confirmation of an indeterminate nodule. a Axial MD map on HAP depicting indeterminate nodule with ROI (blue circle) placed at its centre (blue arrow), ROI (red circle) placed on the background liver parenchyma (orange arrow) and ROI (green circle) within the aorta at the same level (green arrow). b Scatter plot demonstrating ICD nodule HAP for nodule (blue arrow) more than the background liver ICD liver HAP (orange arrow) and less than ICD aorta (green arrow) as reference. c Histopathology confirmation of nodule, showing features of high-grade dysplasia. $\mathbf{d}$ Axial MD map acquired on PVP showing ROI (red circle) placed in the centre of the nodule (blue arrow), ROI (blue circle) on the liver parenchyma (orange arrow), and aorta (green circle) at the same level (green arrow). e Scatter plot demonstrating ICD nodule PVP (blue arrow) persistently higher than $I C D_{\text {liver }}$ PVP (orange arrow). f Immunohistochemistry slide showing CD34-positive foci (black bold arrow) in the nodule depicting dysplasia 
atypical enhancement pattern could be monitored with a high index of suspicion by the radiologist in tandem with the treating physician for stricter surveillance, till the end point of either the nodule exhibiting classical imaging appearance of $\mathrm{HCC}$ or values $>15.5 \mathrm{mg} / \mathrm{mL}$ which has been ascertained as a valid cutoff for malignancy with reference to pathology.

Although beyond the scope of this study, long-term studies would be required to evaluate and sequentially follow-up dysplastic nodules on SCT, regardless of pathology correlation, to look for metamorphosis into HCC and to determine MD values based on natural disease progression. In addition, 'numerical cutoff values' on SCT would simplify the algorithm for diagnosis of nodules in cirrhosis by facilitating 'operator independent', machine-based learning in the future. We feel that extraction of objective MD values will also open the pathway for demarcation of a variety of other benign (e.g., haemangioma, fibronodular hyperplasia) and non-HCC malignant tumours in the liver.

As our objective was to distinguish nodules in cirrhosis using quantitative MD parameters, we have defined three main MD parameters ( $\mathrm{ICD}_{\text {nodule }} \mathrm{HAP}$, LNR-HAP, and $\triangle I C D$ ) and generated cutoff values for differentiation of malignant or potentially malignant and benign nodules in cirrhosis. These are likely to help radiologists gain confidence while reporting 'lesions in question' by circumventing, operator-dependency, scanner limitations, technical parameters, contrast-injection protocols and hemodynamic changes etc. Spectral CT appears as an interesting functional tool for characterisation of nodules in the cirrhotic liver and likely to open a cemented pathway to radiomics in the near future. The incorporation of MD parameters as quantitative and objective criteria for the adequate distinction of these nodules would help in triaging patients for follow-up, further evaluation or intervention. Early therapeutic measures for potentially malignant lesions will open a new window of opportunities in overall disease survival and prognosis.

There were limitations of our study: lack of an adequate number of dysplastic lesions on histopathology for reference; exclusion of other incidental lesions such as haemangiomas; lipomas, complex cysts; fibronodular hyperplasia; or hepatic adenoma from our study cohort. We also excluded non-HCC tumours and most of the atypical HCC or variants such as combined HCCcholangiocarcinoma, during selection of the patient population. We did not use LI-RADS for initial nodule characterisation in addition to the EASL criteria to designate nodules into more than three categories. In the future, studies are required to assess other hepatic focal lesions such as cysts, mimics of HCC and non-HCC malignancies with quantitative $\mathrm{MD}$ parameters for a comprehensive approach. LI-RADS algorithm may also be used in conjunction with MD values for each nodule category in liver cirrhosis.

In conclusion, spectral CT-generated MD parameters, namely $\mathrm{ICD}_{\text {nodule }}$ HAP, LNR-HAP, and $\triangle \mathrm{ICD}$, provided a viable diagnostic tool for differentiating malignant or potentially malignant from benign nodules in cirrhotic patients. Such parameters may represent an add-on diagnostic tool for hepatic nodule characterisation.

\begin{abstract}
Abbreviations
AFP: Alpha-fetoprotein; AUC: Area under the curve; Cl: Confidence interval; EASL: European Association for the Study of the Liver; HAP: Hepatic arterial phase; HCC: Hepatocellular carcinoma; ICD: lodine concentration density; LIRADS: Liver Imaging Reporting and Data System; LNR: Lesion-to-normal ratio; MD: Material density; NIC: Normalised iodine concentration; PVP: Portal venous phase; ROI: Region of interest; SCT: Spectral computed tomography; $\triangle \mathrm{ICD}$ : Delta in iodine concentration density
\end{abstract}

\section{Supplementary Information}

The online version contains supplementary material available at https://doi. org/10.1186/s41747-021-00220-6.

Additional file 1: Supplementary Table 1. Enhancement pattern of nodules ( $n=330$ ) based on size on computed tomography.

Supplementary Table 2. Nominal logistic regression analysis for MD parameter ICD nodule HAP. Supplementary Table 3. Correlation of CT and histopathology diagnosis of nodules with respect to size. Supplementary Table 4. Diagnostic performance of MD parameters on SCT to distinguish malignant versus benign nodules. Supplementary Figure 1. Canonical scores plot representing all cirrhotic nodules in the study. Canonical scores plot to depict overlap of the indeterminate nodules (depicted as red circular area) into either category of HCC and regenerative nodules (green circular plots). Supplementary Figure 2. Classification and regression tree (CART) analysis of ICD nodule HAP.

\section{Acknowledgements}

The authors acknowledge the efforts of Dr. Sarika Shirke for language editing and writing assistance of the manuscript.

\section{Authors' contributions}

STL planned and conducted the study, analysed the data, reviewed the literature, and wrote the manuscript. KY collected and tabulated the scientific data and helped in writing the manuscript. SK helped in conducting the study, interpreted the data, and edited the manuscript. AR performed the histopathological examination. GK interpreted the data and performed the statistical analysis. SKS provided the oversight during the conduct of the study and approved the final version of the manuscript. All authors have critically reviewed and have approved the final version of the manuscript.

\section{Funding}

This research was supported by the YIR SERB grant (YSS/2015/000710). English and technical editing was supported by personal funding.

Availability of data and materials

All data generated or analysed during this study are included in this manuscript and its supplementary information files.

\section{Declarations}

Ethics approval and consent to participate

This retrospective study was approved by the ILBS institutional ethics board. This was a retrospective study; thus, consent to participate was not required.

Consent for publication

Not applicable. 


\section{Competing interests}

The authors declare that they have no competing interests.

\section{Author details}

'Department of Radiology, Institute of Liver and Biliary Sciences, Sector D-1, Vasant Kunj, New Delhi 110070, India. ${ }^{2}$ Department of HPB Surgery and Liver Transplantation, Institute of Liver \& Biliary Sciences, Sector D-1, Vasant Kunj, New Delhi 110070, India. ${ }^{3}$ Department of Clinical and Hepato-pathology, Institute of Liver and Biliary Sciences, Sector D-1, Vasant Kunj, New Delhi 110070, India. ${ }^{4}$ Department of Biostatistics and Research, Institute of Liver \& Biliary Sciences, Sector D-1, Vasant Kunj, New Delhi 110070, India.

${ }^{5}$ Department of Hepatology, Institute of Liver \& Biliary Sciences, Sector D-1, Vasant Kunj, New Delhi 110 070, India.

\section{Received: 4 August 2020 Accepted: 7 April 2021}

\section{Published online: 28 May 2021}

\section{References}

1. Tsochatzis EA, Bosch J, Burroughs AK (2014) Liver cirrhosis. Lancet 383:17491761 https://doi.org/10.1016/S0140-6736(14)60121-5

2. Inchingolo R, Faletti R, Grazioli L et al (2018) MR with Gd-EOB-DTPA in assessment of liver nodules in cirrhotic patients. World J Hepatol 10:462473 https://doi.org/10.4254/wjh.v10.i7.462

3. Choi JY, Lee JM, Sirlin CB (2014) CT and MR imaging diagnosis and staging of hepatocellular carcinoma: part I. Development, growth, and spread: key pathologic and imaging aspects. Radiology 272:635-654 https://doi.org/1 0.1148/radiol.14132361

4. Wanless I (1995) International Working Party. Terminology of nodular hepatocellular lesions. Hepatology 22:983-993 https://doi.org/10.1016/02709139(95)90324-0

5. Park YN, Kim MJ (2011) Hepatocarcinogenesis: imaging-pathologic correlation. Abdom Imaging 36:232-243 https://doi.org/10.1007/s00261-0119688-y

6. Aihara T, Noguchi S, Sasaki Y, Nakano H, Imaoka S (1994) Clonal analysis of regenerative nodules in hepatitis $\mathrm{C}$ virus-induced liver cirrhosis. Gastroenterology 107:1805-1811 https://doi.org/10.1016/0016-5085(94 )90824-9

7. Hayashi M, Matsui O, Ueda K, Kawamori Y, Gabata T, Kadoya M (2002) Progression to hypervascular hepatocellular carcinoma: correlation with intranodular blood supply evaluated with $\mathrm{CT}$ during intraarterial injection of contrast material. Radiology 225:143-149 https://doi.org/10.1148/radiol.2251 011298

8. Borzio M, Fargion S, Borzio F et al (2003) Impact of large regenerative, low grade and high grade dysplastic nodules in hepatocellular carcinoma development. J Hepatol 39:208-214 https://doi.org/10.1016/s0168-8278(03 )00190-9

9. International Consensus Group for Hepatocellular Neoplasia (2009) Pathologic diagnosis of early hepatocellular carcinoma: a report of the international consensus group for hepatocellular neoplasia. Hepatology 49 658-664 https://doi.org/10.1002/hep.22709

10. Roskams T, Kojiro M (2010) Pathology of early hepatocellular carcinoma: conventional and molecular diagnosis. Semin Liver Dis. 30:17-25 https://doi. org/10.1055/s-0030-1247129

11. Sakamoto M (2007) Pathology of early hepatocellular carcinoma. Hepatol Res 37:135-138 https://doi.org/10.1111/j.1872-034X.2007.00176.x

12. Chernyak V, Tang A, Flusberg $M$ et al (2017) LI-RADS(R) ancillary features on CT and MRI. Abdom Radiol (NY) 43:82-100 https://doi.org/10.1007/s00261017-1220-6

13. Kim TH, Kim SY, Tang A, Lee JM (2019) Comparison of international guidelines for noninvasive diagnosis of hepatocellular carcinoma: 2018 update. Clin Mol Hepatol. 25:245-263 https://doi.org/10.3350/cmh.2018.0090

14. Rosiak G, Podgórska J, Rosiak E, Cieszanowski A (2018) CT/MRI LI-RADS v2017 - review of the guidelines. Pol J Radiol 83:355-365 https://doi.org/10. 5114/pjr.2018.78391

15. Narsinh KH, Cui J, Papadatos D, Sirlin CB, Santillan CS (2018) Hepatocarcinogenesis and LI-RADS. Abdom Radiol (NY) 43:158-168 https:// doi.org/10.1007/s00261-017-1409-8

16. Sersté $T$, Barrau V, Ozenne $V$ et al (2011) Accuracy and disagreement of $C T$ and MRI for the diagnosis of small hepatocellular carcinoma and dysplastic nodules: role of biopsy. Hepatology 55:800-806 https://doi.org/10.1002/ hep. 24746
17. European Association for the Study of the Liver (2018) EASL clinical practice guidelines: management of hepatocellular carcinoma. J Hepatol 69:182-236 https://doi.org/10.1016/j.jhep.2018.03.019

18. Navin PJ, Venkatesh SK (2019) Hepatocellular carcinoma: state of the art imaging and recent advances. J Clin Transl Hepatol 7:72-85 https://doi. org/10.14218/JCTH.2018.00032

19. Chernyak V, Fowler KJ, Kamaya A et al (2018) Liver Imaging Reporting and Data System (LI-RADS) version 2018: imaging of hepatocellular carcinoma in at-risk patients. Radiology 289:816-830 https://doi.org/10.1148/radiol.20181 81494

20. Erkan B, Meier J, Clark TJ, Kaplan J, Lambert JR, Chang S (2019) Non-invasive diagnostic criteria of hepatocellular carcinoma: comparison of diagnostic accuracy of updated LI-RADS with clinical practice guidelines of OPTNUNOS, AASLD, NCCN, EASL-EORTC, and KLSCG-NCC. PLOS One 14:e0226291 https://doi.org/10.1371/journal.pone.0226291

21. McCollough CH, Leng S, Yu L, Fletcher JG (2015) Dual- and multi-energy CT: principles, technical approaches, and clinical applications. Radiology 276 637-653 https://doi.org/10.1148/radiol.2015142631

22. Wu L, Cao G, Zhao L et al (2018) Spectral CT analysis of solitary pulmonary nodules for differentiating malignancy from benignancy: the value of iodine concentration spatial distribution difference. Biomed Res Int 3:1-9 https:// doi.org/10.1155/2018/4830659

23. Zhang $Y$, Cheng J, Hua $X$ et al (2016) Can spectral CT imaging improve the differentiation between malignant and benign solitary pulmonary nodules? PLoS One 11:e0147537 https://doi.org/10.1371/journal.pone.0147537

24. George E, Wortman JR, Fulwadhva UP, Uyeda JW, Sodickson AD (2017) Dual energy CT applications in pancreatic pathologies. Br J Radiol 90:20170411 https://doi.org/10.1259/bjr.20170411

25. Karçaaltıncaba M, Aktaş A (2011) Dual-energy CT revisited with multidetector CT: review of principles and clinical applications. Diagn Interv Radiol 17:181-194 https://doi.org/10.4261/1305-3825.DIR.3860-10.0

26. Foley WD, Kerimoglu U (2004) Abdominal MDCT: liver, pancreas, and biliary tract. Semin Ultrasound CT MR 225:122-144 https://doi.org/10.1016/j.sult.2 003.12 .001

27. Johnson TR, Krauss B, Sedlmair M et al (2007) Material differentiation by dual energy CT: initial experience. Eur Radiol 17:1510-1517 https://doi.org/1 0.1007/s00330-006-0517-6

28. Robinson E, Babb J, Chandarana H, Macari M (2010) Dual source dual energy MDCT: comparison of $80 \mathrm{kVp}$ and weighted average $120 \mathrm{kVp}$ data for conspicuity of hypo-vascular liver metastases. Invest Radiol 45:413-418 https://doi.org/10.1097/RLI.0b013e3181dfda78

29. Goo HW, Goo JM (2017) Dual-energy CT: new horizon in medical imaging. Korean J Radiol 18:555-569 https://doi.org/10.3348/kjr.2017.18.4.555

30. Laroia ST, Bhadoria AS, Venigalla $Y$ et al (2016) Role of dual energy spectral computed tomography in characterization of hepatocellular carcinoma: initial experience from a tertiary liver care institute. Eur J Radiol Open 3:162171 https://doi.org/10.1016/j.ejro.2016.05.007

31. Murray N, Darras KE, Walstra FE, Mohammed MF, McLaughlin PD, Nicolaou S (2019) Dual-energy CT in evaluation of the acute abdomen. Radiographics 39:264-286 https://doi.org/10.1148/rg.2019180087

32. Li C, Lin X, Hui C, Lam KM, Zhang S (2016) Computer-aided diagnosis for distinguishing pancreatic mucinous cystic neoplasms from serous oligocystic adenomas in spectral CT images. Technol Cancer Res Treat 15: 44-54 https://doi.org/10.1177/1533034614563013

33. $X u$ R, Wang J, Huang $X$ et al (2019) Clinical value of spectral CT imaging combined with AFP in identifying liver cancer and hepatic focal nodular hyperplasia. J BUON 24:1429-1434 PMID: 31646787

34. Yu Y, He N, Sun K, Lin X, Yan F, Chen K (2013) Differentiating hepatocellular carcinoma from angiomyolipoma of the liver with $\subset$ spectral imaging: a preliminary study. Clin Radiol 68:491-497 https:/doi.org/10.1016/j.crad.2013.03.027

35. LV P, Lin XZ, Chen K, Gao J (2012) Spectral CT in patients with small HCC: investigation of image quality and diagnostic accuracy. Eur Radiol 22:21172124 https://doi.org/10.1007/s00330-012-2485-3

36. Lv P, Lin XZ, Li J, Li W, Chen K (2011) Differentiation of small hepatic hemangioma from small hepatocellular carcinoma: recently introduced spectral CT method. Radiology 259:720-729 https://doi.org/10.1148/ra diol.11101425

37. Pfeiffer D, Parakh A, Patino M, Kambadakone A, Rummeny EJ, Sahani DV (2018) lodine material density images in dual-energy CT: quantification of contrast uptake and washout in HCC. Abdom Radiol (NY) 43.3317-3323 https://doi.org/10.1007/s00261-018-1636-7 
38. Kaltenbach B, Wichmann JL, Pfeifer S et al (2018) lodine quantification to distinguish hepatic neuroendocrine tumor metastasis from hepatocellular carcinoma at dual-source dual-energy liver CT. Eur J Radiol 105:20-24 https://doi.org/10.1016/j.ejrad.2018.05.019

39. Anzidei M, Di Martino M, Sacconi B et al (2015) Evaluation of image quality, radiation dose and diagnostic performance of dual-energy $\mathrm{CT}$ datasets in patients with hepatocellular carcinoma. Clin Radiol 70:966-973 https://doi. org/10.1016/j.crad.2015.05.003

40. European Association for the Study of the Liver (2012) EASL-EORTC clinical practice guidelines: management of hepatocellular carcinoma. J Hepatol 56: 908-943 https://doi.org/10.1016/j.jhep.2011.12.001

41. Ronot M, Dioguardi Burgio M, Purcell Y, Pommier R, Brancatelli G, Vilgrain V (2017) Focal lesions in cirrhosis: not always HCC. Eur J Radiol 93:157-168 https://doi.org/10.1016/j.ejrad.2017.05.040

42. lavarone $M$, Viganò $M$, Piazza $N$ et al (2019) Contrast imaging techniques to diagnose hepatocellular carcinoma in cirrhotics outside regular surveillance. Ann Hepatol 18:318-324 https://doi.org/10.1016/j.aohep.2018.09.002

43. Gao L, LV Y, Jin Y et al (2019) Differential diagnosis of hepatic cancerous nodules and cirrhosis nodules by spectral CT imaging: a feasibility study. Acta Radiol 60:1602-1608 https://doi.org/10.1177/0284185119840230

44. Hou WS, Wu HW, Yin Y, Cheng JJ, Zhang Q, Xu JR (2015) Differentiation of lung cancers from inflammatory masses with dual-energy spectral CT imaging. Acad Radiol 22:337-344 https://doi.org/10.1016/j.acra.2014.10.004

45. Li L, Zhao Y, Luo D et al (2018) Diagnostic value of single-source dualenergy spectral computed tomography in differentiating parotid gland tumors: initial results. Quant Imaging Med Surg 8:588-596 https://doi.org/1 0.21037/qims.2018.07.07

46. Li M, Zheng X, Li J et al (2012) Dual-energy computed tomography imaging of thyroid nodule specimens: comparison with pathologic findings. Invest Radiol 47:58-64 https://doi.org/10.1097/RLI.0b013e318229fef3

47. Yin Q, Zou X, Zai X et al (2015) Pancreatic ductal adenocarcinoma and chronic mass-forming pancreatitis: differentiation with dual-energy MDCT in spectral imaging mode. Eur J Radiol 84:2470-2476 https://doi.org/10.1016/j. ejrad.2015.09.023

48. Matsui O (2004) Imaging of multistep human hepatocarcinogenesis by CT during intra-arterial contrast injection. Intervirology 47:271-276 https://doi. org/10.1159/000078478

49. Fletcher JG, Takahashi N, Hartman R et al (2009) Dual-energy and dualsource CT: is there a role in the abdomen and pelvis? Radiol Clin North Am 47:41-57 https://doi.org/10.1016/j.rcl.2008.10.003

50. Matsui O, Kobayashi S, Sanada J et al (2011) Hepatocelluar nodules in liver cirrhosis: hemodynamic evaluation (angiography-assisted CT) with special reference to multi-step hepatocarcinogenesis. Abdom Imaging 36:264-272 https://doi.org/10.1007/s00261-011-9685-1

51. Cho HJ, Kim B, Lee JD et al (2017) Development of risk prediction model for hepatocellular carcinoma progression of indeterminate nodules in hepatitis B virus-related cirrhotic liver. Am J Gastroenterol 112:460-470 https://doi. org/10.1038/ajg.2016.480

52. Rizal S, Joshi BR, Singh AG (2019) Burden of alcoholic liver disease in a tertiary care center: a descriptive cross-sectional study. JNMA J Nepal Med Assoc 57:307-310 https://doi.org/10.31729/jnma.4631

53. Robinson P (2008) Hepatocellular carcinoma: development and early detection. Cancer Imaging 8:128-131 https://doi.org/10.1102/1470-7330.2 008.9019

\section{Publisher's Note}

Springer Nature remains neutral with regard to jurisdictional claims in published maps and institutional affiliations.

\section{Submit your manuscript to a SpringerOpen ${ }^{\circ}$ journal and benefit from:}

- Convenient online submission

- Rigorous peer review

- Open access: articles freely available online

- High visibility within the field

- Retaining the copyright to your article

Submit your next manuscript at $\boldsymbol{\nabla}$ springeropen.com 